\title{
Animasi 2D Motion Graphic "Zeta dan Dimas" sebagai Media Pendidikan Berlalu Lintas bagi Anak Usia Dini
}

\author{
Riky Taufik Afif \\ Program Studi Desain Komunikasi Visual, Fakultas Industri Kreatif \\ Universitas Telkom, Jl. Telekomunikasi No. 1, Bandung \\ E-mail:rtaufikafif@telkomuniversity.ac.id
}

\begin{abstract}
Abstrak
Anak usia dini pada dasarnya perlu input pendidikan tata nilai tentang kehidupan sosial. Salah satunya adalah tentang cara mereka bersikap tentang berlalu lintas. Penelitian ini menggunakan metode kualitatif. Dinas Perhubungan Kabupaten Bandung memiliki Taman Pendidikan Lalu Lintas yang diberi nama Taman Pacantells. Di Taman Pacantells terdapat instrumen dan alat pendidikan seputar lalu lintas di jalan raya. Alat peraga dan adanya taman Pacantells dianggap kurang dan perlu adanya sebuah tayangan animasi yang bersifat menjelaskan kepada anak usia dini tentang tertib dan aman berlalu lintas di jalan. Tayangan animasi motion graphic ini menampilkan tokoh karakter yang juga adalah maskot dari Dinas Perhubungan Kabupaten Bandung yaitu Zeta dan Dimas yang memandu penonton dari kalangan anak usia dini di Taman Pacantells mendapatkan panduan tentang bagaimana bersikap yang baik dalam berlalu lintas seperti ketika menyeberang, berjalan di tepi jalan, macam-macam rambu-rambu lalu lintas dan lain sebagainya.
\end{abstract}

Kata kunci: Animasi, lalu lintas, pendidikan, usia dini.

\begin{abstract}
Early childhood needs the input of value education about social life. One is about the way they behave in traffic. This study uses qualitative methods. Bandung District Transportation Office has a Traffic Education Park named Taman Pacantells. In Pacantells Park there are educational instruments and tools around the highway traffic. Props and the existence of Pacantells park are considered lacking and there needs to be an animated question that explains to early childhood about the orderly and safe traffic on the road. This animated motion graphic show features a character who is also the mascot of the Bandung District Transportation Office, Zeta and Dimas who guide the audience from an early age in Pacantells Park to get guidance on how to be good in traffic such as when crossing, walking on the side of the road, various traffic signs and so on.
\end{abstract}

Keywords: Animation, traffic, education, early childhood.

\section{Pendahuluan}

Pada anak usia dini perlu adanya transfer pengetahuan dan pendidikan seputar tata cara bersikap dan bersosialisasi. Tentu pada dasarnya anak-anak tidak memiliki tata nilai yang digunakan sebagai pedoman kehidupannya. Tata nilai pada anak-anak dibangun melalui pendidikan yang diterima. Dalam prosesnya, anak usia dini melihat orang tua mereka dan juga orang-orang disekitar mereka menjadi role model mereka dalam bersikap dan untuk dicontoh dalam kehidupan sehari-hari. Selain orang tua yang menjadi role model pertama bagi anak-anak dalam masa pertumbuhannya, anak-anak juga belajar dan melihat dari lingkungan disekitarnya.
Setiap individu mengalami perkembangan. Perkembangan terjadi sejak usia dini hingga dewasa. Perkembangan tidak dapat diukur, tetapi dapat dirasakan. Perkembangan bersifat maju ke depan (progresif), sistematis, dan berkesinambungan (Khaironi, 2018). Perkembangan dimulai dari masa kanakkanak sejak masih usia dini terus bertumbuh seiring bertambahnya usia dan pengetahuan yang diperoleh seorang individu. Salah satu instrumen penting perkembangan manusia pada kategori usia dini adalah pendidikan. Pendidikan menjadikan anak-anak dalam masa tumbuh kembangnya menjadi memiliki patokan dasar nilai yang diambil oleh anakanak dalam masa tumbuh kembangnya sebagai 
alasan berperilaku dan bersikap. Dasar-dasar nilai pada anak-anak sangat ditentukan oleh pendidikan diantaranya yang paling penting adalah pendidikan dirumah oleh orang tua kemudian pendidikan dilingkungan sekitar pergaulannya dan juga hasil pendidikan di sekolah apabila anak tersebut sudah memasuki usia sekolah minimal masuk kategori pendidikan anak usia dini (PAUD).

Peran pendidikan salah satunya adalah tentang bagaimana anak usia dini diberikan asupan nilai-nilai seputar berlalu lintas, bagaimana cara menyeberang di jalan, bagai-mana cara membaca rambu-rambu lalu lintas, bagaimana cara berjalan di tepi jalan ketika ada banyak kendaraan melintas. Pendidikan berlalu lintas bagi anak-anak sangat penting terlebih bagi anak-anak yang hidup dan tumbuh di kota-kota besar. Anak-anak yang tumbuh berkembang di kota-kota besar akan sering berinteraksi dengan kendaraan yang melintas di jalan. Minimal mereka akan sering melihat kendaraan atau bahkan bermain disekitar kendaraan melintas dan berlalu lalang.

Tidak menutup kemungkinan bagi anak-anak yang tumbuh di pedesaan dan pinggiran kota. Mereka sangat mungkin untuk bertemu kendaraan dan jalan raya dalam kehidupan dan proses tumbuh kembangnya.

Masa anak usia dini merupakan masa keemasan atau sering disebut golden Age. Anak usia dini adalah anak yang berada pada rentang usia 0-6 tahun. Pada usia tersebut, perkembangan terjadi sangat pesat. Berdasarkan hasil penelitian, sekitar $40 \%$ dari perkembangan manusia terjadi pada usia dini. Oleh karena itu, usia dini dipandang sangat penting sehingga diistilahkan usia emas (golden age) (Khairani, 2018). Pada masa ini otak anak mengalami perkembangan paling cepat sepanjang sejarah kehidupannya. Hal ini berlangsung pada saat anak dalam kandungan hingga usia dini, yaitu usia nol sampai enam tahun (Fauziddin M, 2016). Sehingga, pada periode golden age ini anak-anak usia dini sangat tepat diberikan asupan nilai-nilai pendidikan agar kedepan dapat terbentuk karakter pribadi yang baik dan dapat bersosialisasi dengan masyarakat ketika sudah dewasa. Salah satu yang menjadi instrumen pendidikan sosial dan kecakapan pada anak usia dini adalah pendidikan transfer nilai tentang pengetahuan bagaimana berlalu lintas.
Taman Pacantells didirikan Dinas Perhubungan Kabupaten Bandung agar menjadi media edukasi berlalu lintas bagi anak usia dini. Salah satu instrumen pendidikan berlalu lintas bagi anak usia dini di Taman Pacantells adalah adanya karakter Zeta dan Dimas yang menjadi maskot Taman Pacantells Dinas Perhubungan Kabupaten Bandung.

Awalnya di Taman Pacantells hanya ada pemandangan miniatur lalu lintas di jalan raya saja. Kemudian pada perkembangannya, karena Taman Pacantells diperuntukan untuk anak usia dini dan sebagai media pembelajaran berlalu lintas bagi anak-anak usia dini di PAUD Kabupaten Bandung maka diprakarsailah maskot dari karakter yang dapat memandu anak-anak usia dini ketika datang ke Taman Pacantells. Karakter ini harus memiliki penampilan dan karakteristik yang dekat dengan anak-anak usia dini juga membawa budaya dan ciri khas dari jalan raya. Dibuatlah karakter Zeta yang diambil inspirasinya dari zebra cross yang biasa digunakan untuk menyebrang jalan. Karakter Zeta dibuat persis seperti hewan zebra, berwarna dan bercorak garisgaris hitam dan putih. Karakter Zeta juga memakai pakaian rompi yang biasa digunakan oleh petugas Dinas Perhubungan ketika dijalan.

Karakter Zeta saja dianggap kurang cukup, perlu ada karakter pendamping yang menjadi rekan dari Zeta ketika menjalankan tugasnya membimbing dan menemani anak-anak usia dini di Taman Pacantells dan muncul sosok karakter Dimas. Karakter Dimas ini mengambil inspirasi dari sosok petugas Dinas Perhubungan yang ada dilapangan. Sosok Dimas adalah sosok manusia karena betulbetul menggambil inspirasi dari karakter dan penampilan petugas Dinas Perhubungan yang ada dikantor-kantor Dinas Perhubungan dan juga yang ada dijalan. Dua karakter ini di desain berpenampilan lucu dan dekat dengan karakteristik yang disukai anak-anak usia dini.

Karakter Dimas dan Zeta pada awal kemunculannya hanya bertugas menyambut, menemani dan memandu anak-anak usia dini yang datang ke Taman Pacantells untuk berkeliling di Taman Pacantells, memandu apa saja yang ada di Taman Pacantells, fungsi alatalat yang ada disana. Dimas dan Zeta juga mengajarkan dan mengenalkan rambu-rambu 
lalu lintas kepada anak-anak tentang makna dan fungsi dari setiap rambu-rambu lalu lintas yang sering ditemukan di jalan raya. Dimas dan Zeta memandu anak-anak usia dini di Kabupaten Bandung yang datang ke Taman Pacantells bagaimana cara berjalan kaki yang baik dan benar ketika dijalan dan juga cara menyeberang yang aman ketika melintas dijalan bagi anak-anak usia dini agar selamat dan tidak terjadi kecelakaan yang dapat membahayakan keselamatan anak-anak ketika menyeberang dijalan.

Ketika Dimas dan Zeta memandu kegiatan anak-anak usia dini di Taman Pacantells, anak-anak terlihat kegirangan dan selalu mengikuti kemana Dimas dan Zeta mengarahkan anak-anak untuk bergerak berkeliling Taman Pacantells. Anak-anak yang berkunjung seolah-olah mendapat teman bermain yang baru karena maskot Dimas dan Zeta di Taman Pacantells bertingkah dan bersikap layaknya anak-anak usia dini. Banyak anakanak yang datang hanya untuk bisa berfoto dengan Dimas dan Zeta, minta agar dipeluk dan bahkan menarik-narik lengan Dimas dan Zeta. Selain memandu berkeliling Taman Pacantells, maskot Dimas dan Zeta juga mengajar anak-anak untuk bernyanyi dan menari ketika berada di Taman Pacantells kadangkadang Dimas dan Zeta juga mengajak anakanak untuk senam lalu lintas bersama sambil mengenalkan makna dari rambu-rambu lalu lintas yang sering ada di pinggir-pinggir jalan.

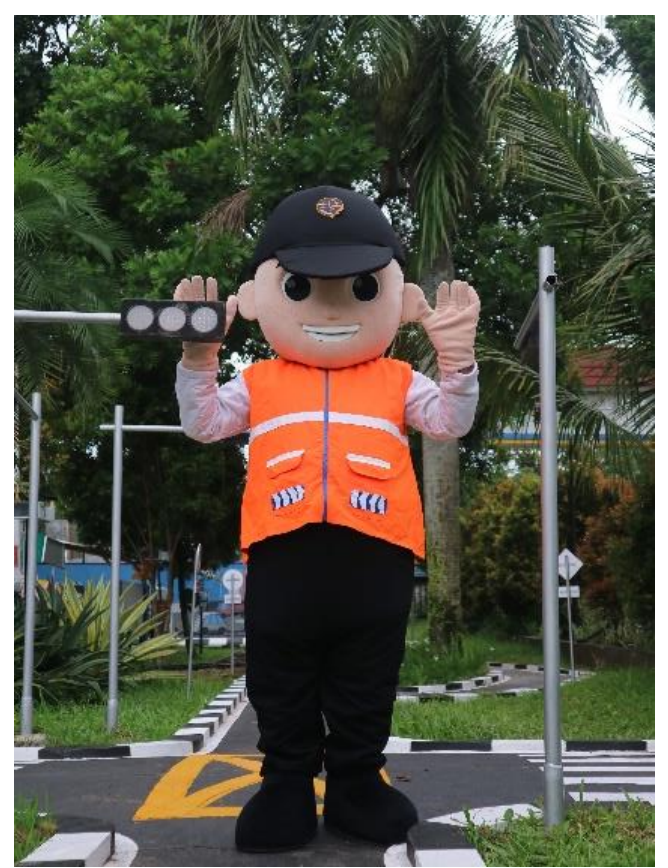

Gambar 1. Karakter Dimas dalam kostum di Taman Pacantells.

Sumber: Dinas Perhubungan Kab. Bandung, 2020
Melihat animo anak-anak usia dini yang datang ke Taman Pacantells pada karakter Dimas dan Zeta, juga sudah melekat di ingatan anak-anak pengunjung Taman Pacantells tentang Dimas dan Zeta sebagai maskot di Taman Pacantells maka dibuatlah tayangan animasi Dimas dan Zeta sebagai media edukasi tambahan tentang berlalu lintas di Taman Pacantells. Sehingga Dimas dan Zeta sebagai maskot Taman Pacantells tidak hanya dapat disaksikan langsung secara fisik namun dapat disaksikan juga secara virtual dalam tayangan animasi. Animasi Dimas dan Zeta dapat disaksikan setiap anak-anak usia dini dari PAUD disekitar Kabupaten Bandung datang dan berkunjung ke Taman Pacantells. Bukan hanya anak-anak PAUD, masyarakat sekitar pun dapat berkunjung dan melihat tayangan animasi Dimas dan Zeta di Taman Pacantells.

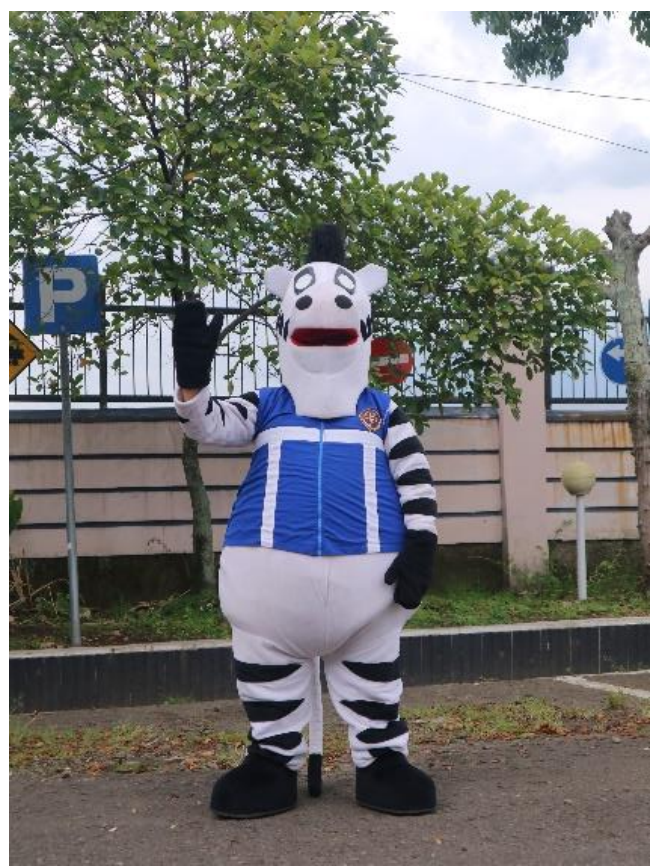

Gambar 2. Karakter Zeta dalam kostum di Taman Pacantells.

Sumber: Dinas Perhubungan Kab. Bandung, 2020

Karakter Zeta dan Dimas dimunculkan dalam tayangan animasi pendidikan dalam format motion graphic yang menyuguhkan pendidikan berlalu lintas bagi anak usia dini di Kabupaten Bandung. Adanya tayangan animasi edukasi di Taman Pacantells diharapkan dapat mendorong tujuan pendidikan bagi anak usia dini. Tujuan Pendidikan Anak Usia Dini (PAUD) menurut Undang-Undang nomor 20 tahun 2003 tentang sistem pendidikan nasional dinyatakan bahwa pendidikan anak usia dini adalah sebagai suatu upaya pembinaan yang ditujukan kepada anak sejak lahir sampai dengan usia enam tahun yang dilakukan 
melalui pemberian rangsangan pendidikan untuk membantu pertumbuhan dan perkembangan jasmani dan rohani agar anak memiliki kesiapan dalam memasuki pendidikan lebih lanjut (Indonesia, 2003).

Kemudian dijelaskan lebih dalam dalam Permendikbud nomor 37 tahun 2014 dijelaskan bahwa pendidikan anak usia dini merupakan pendidikan yang ditujukan pada anak usia untuk merangsang dan memaksimalkan aspekaspek perkembangannya. Terdapat 6 aspek perkembangan yang harus dikembangkan oleh guru Pendidikan Anak Usia Dini (PAUD). Keenam aspek tersebut adalah aspek perkembangan nilai agama dan moral, koginitf, sosial emosional, Bahasa, fisik motorik, dan seni (Kemendikbud, 2014).

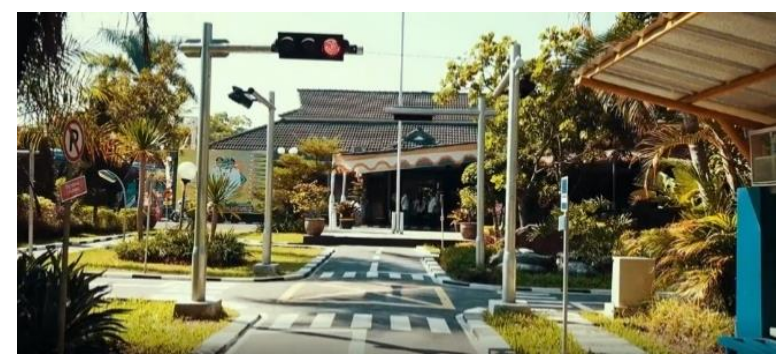

Gambar 3. Suasana Taman Pacantells Sumber: Dokumentasi pribadi, 2021

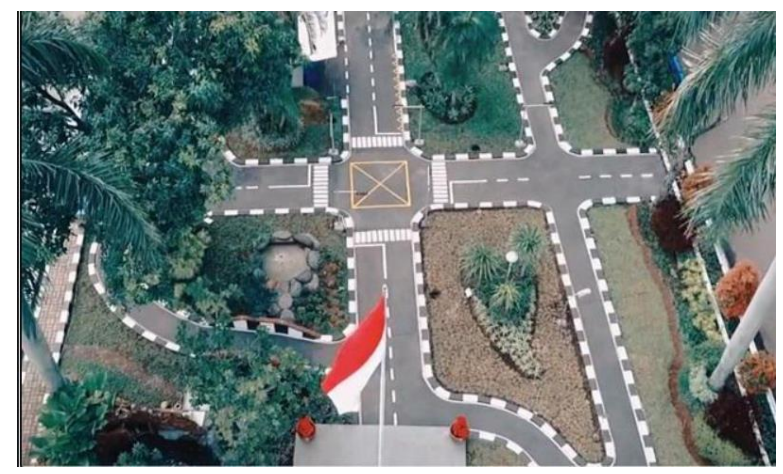

Gambar 4. Suasana Taman Pacantells dari atas. Sumber: berita.baca.co.id, 2021

Dengan media animasi motion graphic diharapkan dapat menjadi media pendidikan yang kreatif bagi anak usia dini yang dalam hal ini menjadi objek transfer nilai pendidikan. Menurut Suheri, media animasi dapat memberikan efektivitas transfer nilai pendidikan dalam bentuk informasi lebih efektif. Perubahan dari media visual gambar diam ke multimedia animasi ini diharapkan setiap siswa dapat menyamakan persepsi untuk penjelasan isi materi yang disampaikan oleh guru (Suheri, 2006). Dalam hal ini siswa yang dimaksud adalah anak usia dini dari PAUD disekitar taman Pacantells yang berkunjung ke taman Pacantells menyaksikan animasi Zeta dan Dimas kemudian mendapat informasi pendidikan seputar berlalu lintas dari animasi Dimas dan Zeta. Sehingga transfer nilai pendidikan lebih efektif disampaikan dengan media kreatif animasi motion graphic Dimas dan Zeta ini.

\section{Metode Penelitian}

Pada penelitian ini penulis menggunakan metode penelitian kualitatif. Pendekatan kualitatif sangat ideal digunakan pada penelitian analisis seperti analisis pada karya animasi Dimas dan Zeta di Taman Pacantells ini. Metode penelitian kualitatif menurut Sugiono (2015) adalah metode penelitian yang digunakan untuk meneliti pada kondisi objek yang alamiah di mana peneliti adalah sebagai instrumen kunci. Teknik pengumpulan data dilakukan secara triansgulasi (gabungan), analisis data bersifat induktif, dan hasil penelitian kualitatif lebih menekankan makna daripada generalisasi.

Dalam proses pengolahan dan pemaparan data penilitian penulis menggunakan data alamiah yang ada dilapangan. Adapun penekanan pengolahan data berpusat pada objek yang diteliti yaitu karya animasi 2D motion graphic yang berisi nilai-nilai edukasi dan transfer pendidikan berlalu lintas bagi anak usia dini di taman Pacantells. Menurut Darojah (2011) media film animasi merupakan media audio visual berupa rangkaian gambar tak hidup yang berurutan pada frame dan diproyeksikan secara mekanis elektronis sehingga tampak hidup pada layar.

Harapan penulis dengan menggunakan metode kualitatif maka dapat diperoleh data yang komprehensif tentang animasi Zeta dan Dimas sebagai media edukasi dan pendidikan berlalu lintas. Juga dapat menguraikan analisis tentang karakter Dimas dan Zeta yang di elaborasikan dengan karya animasi 2D motion graphic menurut Maleong (2016) Penelitian kualitatif menggunakan metode kualitatif yaitu pengamatan, wawancara, atau penelaahan dokumen. Metode kualitatif ini digunakan karena beberapa pertimbangan. Pertama menyesuaikan metode kualitatif lebih mudah apabila berhadapan dengan kenyataan jamak. Kedua, metode ini meyajikan secara langsung hakikat hubungan antara peneliti dan responden. Ketiga, metode ini lebih peka dan lebih dapat meyeseuaikan diri dengan banyak penajaman pengaruh bersama terhadap 
pola-pola nilai yang dihadapi.

Dengan pendekatan kualitatif diharapkan dapat dihasilkan data penelitian yang menyimpulkan dampak animasi 2D motion graphic Dimas dan Zeta pada proses pendidikan berlalu lintas anak usia dini di taman Pacantells dengan akurat dan lengkap.

\section{Hasil dan Pembahasan}

Pada bagian hasil penelitian penulis ingin menguraikan hasil dari penelitian berupa proses mengolah data, wawancara dan hasil pengamatan dilapangan.

Anak-anak yang berkunjung ke Taman Pacantells di Kabupaten Bandung mayoritas adalah anak-anak yang merupakan peserta didik dari PAUD di Kabupaten Bandung. Tidak sedikit juga anak-anak yang berkunjung di waktu sore atau di waktu libur didampingi oleh orang tuanya untuk bermain di Taman Pacantells. Taman Pacantells selain taman edukasi berlalu lintas juga taman bermain bagi anak-anak.

Pada momen-momen tertentu seperti perayaan hari kemerdekaan Indonesia 17 Agustus, Taman Pacantells juga digunakan sebagai tempat bermain dan mengadakan lomba dalam merayakan hari ulang tahun kemerdekaan Indonesia berupa balap mobil-mobilan, makan kerupuk, adu tangkas dan lain sebagainya yang notabene perlombaan dan kegiatan yang hanya di ikuti oleh anak-anak saja. Dalam pelaksanaannya di Taman Pacantells sebagai tempat edukasi dan bermain tidak jarang dihadiri oleh pejabat dari Dinas Perhubungan Kabupaten Bandung sendiri untuk ikut memeriahkan.

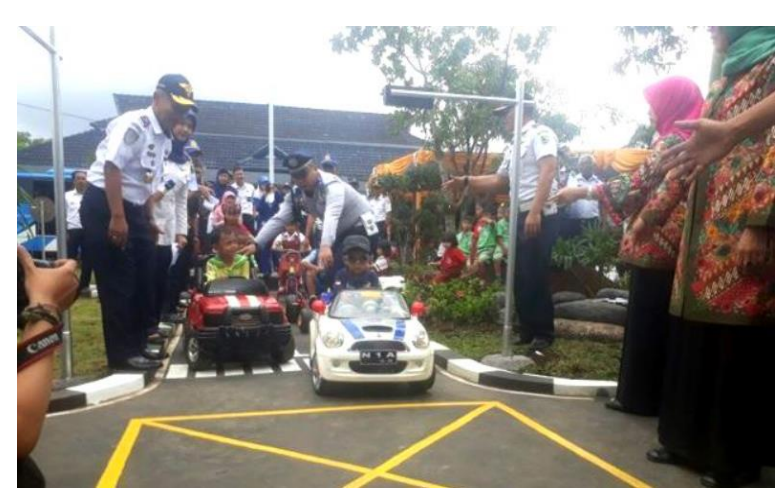

Gambar 5. Penampilan Karakter Dimas pada Maskot Fisik.

Sumber: Dinas Perhubungan Kab. Bandung, 2020.

Anak-anak belum mengenal dan melihat karakter Dimas dan Zeta sebelumnya. Mereka baru pertama kali melihat Dimas dan Zeta ketika berkunjung ke Taman Pacantells. Animasi Dimas dan Zeta, pada penampilan karakternya di tayangan animasi tersebut ada beberapa perubahan dari wujud maskot fisiknya.

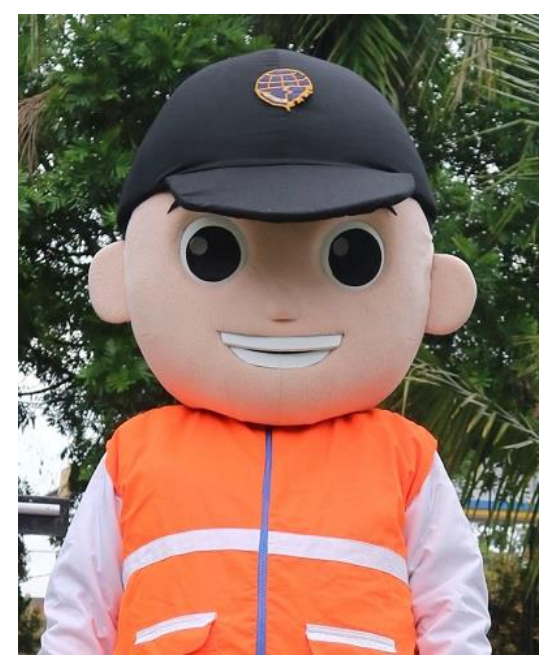

Gambar 6. Penampilan Karakter Dimas pada Maskot Fisik.

Sumber: Dinas Perhubungan Kab. Bandung, 2020

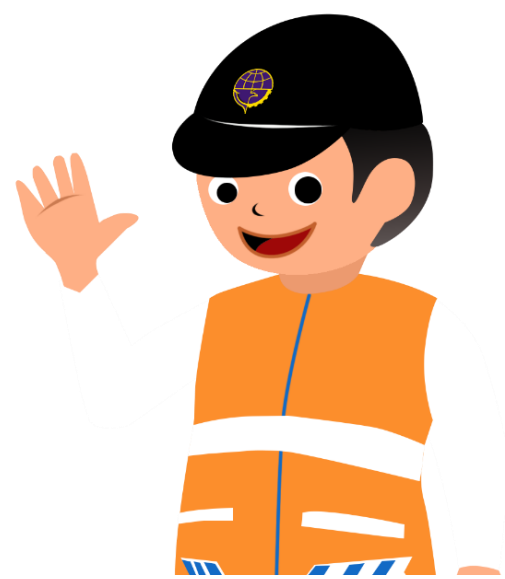

Gambar 7. Penampilan Karakter Dimas di Animasi Dimas dan Zeta

Sumber: Dinas Perhubungan Kab. Bandung, 2020.

Perubahan pada penampilan karakter Dimas dan Zeta di tanyangan animasi Dimas dan Zeta bertujuan agar terlihat lebih lucu dan dekat dengan karakter anak-anak usia dini. Gambar yang lebih lucu dan imut dipandang dapat lebih berhasil meraih simpati anak-anak agar tujuan penyampaian nilai-nilai pendidikan berlalu lintas juga sukses tersampaikan. Keberhasilan proses pembelajaran dipengaruhi beberapa faktor, seperti faktor guru, siswa, media, dan lingkungan (Sanjaya, 2009). Animasi Dimas dan Zeta dipandang sebagai media pembelajaran yang tepat bagi anak-anak usia dini yang belum dapat membaca dan berhitung dengan baik. Tayangan visual berupa film sangat 
membantu mereka mendapatkan maksud dan tujuan dari tayangan animasi Dimas dan Zeta berupa transfer nilai-nilai bagaimana berlalu lintas yang baik meliputi pengetahuan seputar rambu-rambu lalu lintas di jalan. Selain itu juga membantu bagaimana cara menyikapi rambu-rambu tersebut, kemudian bagaimana cara menyeberang di jalan yang baik dan benar agar selamat. Ditunjukkan juga tips agar aman dalam menyeberang serta memberikan edukasi seputar pendamping di jalan di mana anakanak dalam menyeberang memerlukan pendamping agar menyeberang jalan dengan baik dan selamat.

Kaitannya dalam menyampaikan nilai-nilai pendidikan diatas sangat memerlukan media pembelajaran yang tepat dalam hal ini tayangan animasi Dimas dan Zeta adalah media pembelajaran yang efektif dalam menyampaikan nilai-nilai pendidikan berlalu lintas bagi anak usia dini yang notabene belum bisa membaca dan menulis.

Media pembelajaran yang tepat juga dapat mengarahkan perhatian anak sehingga dapat menimbulkan motivasi belajar, dan membantu siswa untuk belajar mandiri sesuai dengan kemampuan sertaminatnya (Azwandi, 2007).

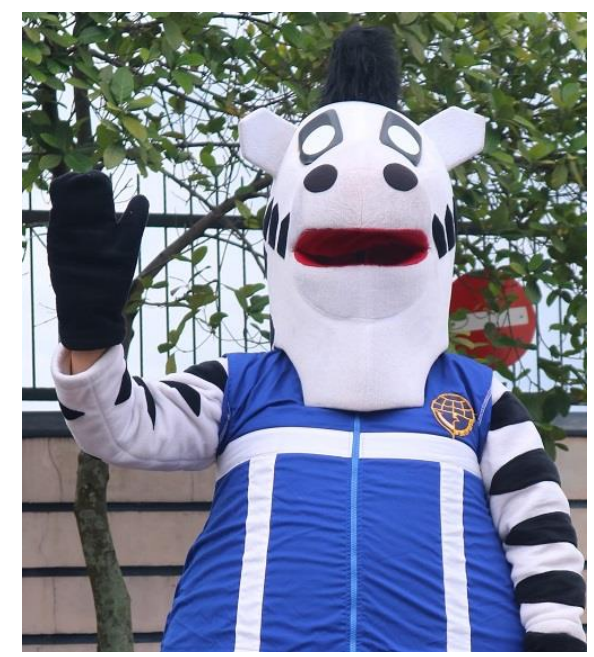

Gambar 8. Penampilan Karakter Zeta pada Maskot Fisik

Sumber: Dinas Perhubungan Kab. Bandung, 2020

Perubahan penampilan karakter di tayangan animasi Dimas dan Zeta dimaksudkan agar penyampaian nilai-nilai pendidikan berlalu lintas dapat tersampaikan. Tayangan animasi atau film animasi digunakan untuk memenuhi suatu kebutuhan umum yaitu mengkomunikasikan suatu gagasan, pesan atau kenyataan (Raimukti, 2013). Penampilan baru Dimas dan Zeta pada tayangan animasi tentu menarik perhatian anak-anak usia dini yang datang berkunjung ke Taman Pacantells. Animasi Dimas dan Zeta telah menarik perhatian anakanak karena memang pemanfaatan film animasi dalam proses pembelajaran dapat meningkatkan kualitas proses dan hasil belajar, karena film animasi bersifat menarik (Hasanah $\mathrm{dkk}, 2015)$.

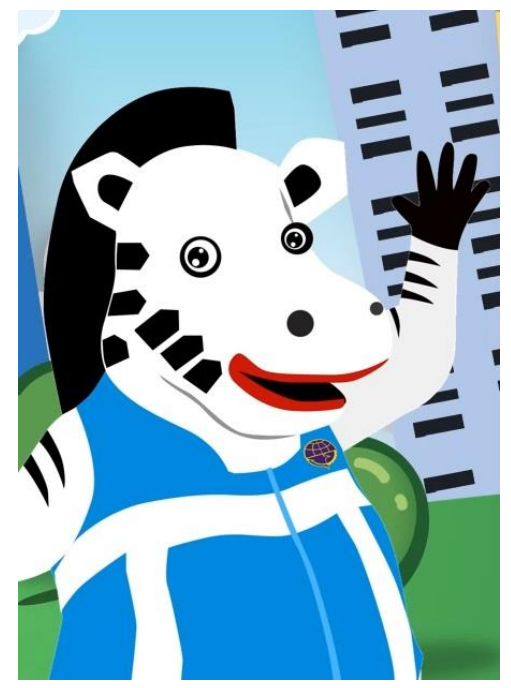

Gambar 9. Penampilan Karakter Zeta di Animasi Dimas dan Zeta.

Sumber: Dinas Perhubungan Kab. Bandung, 2020

Berdasarkan pemaparan diatas, meliputi penyajian visual karakter Dimas dan Zeta pada tayangan animasinya juga melihat desain karakter Dimas dan Zeta yang menarik dan dekat dengan karakter anak-anak terdapat antusiasme anak-anak usia dini di taman Pacantells yang menyaksikan peraga kostum Dimas dan Zeta juga animasi Dimas dan Zeta yang memberikan edukasi berlalu lintas. Antusiasme anak-anak usia dini yang berkunjung terlihat dari mulai datang ke Taman Pacantells anak-anak selalu mengikuti kemana pun maskot Dimas dan Zeta pergi, mengikuti sampai kegiatan berakhir dan ditutup dengan menari bersama.

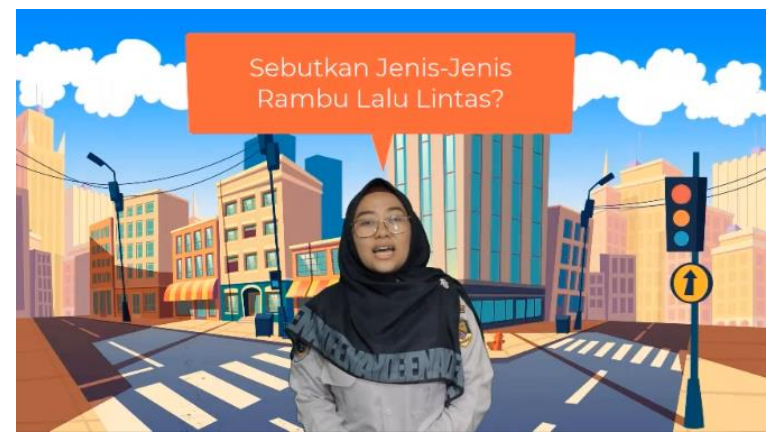

Gambar 10. Pembawaan Kuis di Akhir Tayangan Animasi Dimas dan Zeta

Sumber: Dinas Perhubungan Kab. Bandung, 2020 
Ketika animasi Dimas dan Zeta ditayangkan, anak-anak usia dini yang menyaksikan mengikuti dari awal ditayangkan sampai selesai. Mengikuti setiap kuis yang ditayangkan di animasi tersebut dan mengikuti gerakan senam yang ada di tayangan animasi Dimas dan Zeta sambil tertawa lepas bahagia.

Dari animasi Dimas dan Zeta, anak-anak usia dini dapat menyerap informasi tentang jenisjenis rambu-rambu lalu lintas dan bagaimana menyeberang serta berjalan kaki di pinggir jalan dengan aman.

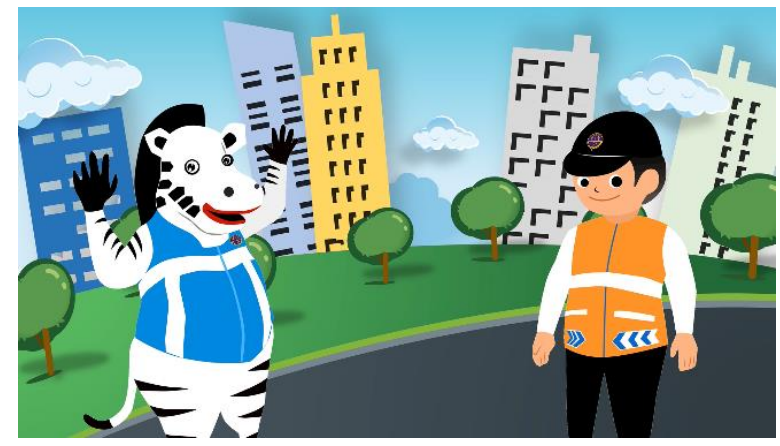

Gambar 11. Pengenalan Dimas dan Zeta di Tayangan Animasi 2D Motion Graphic Dimas dan Zeta

Sumber: Dinas Perhubungan Kab. Bandung, 2020

Pada animasi 2D tersebut Dimas dan Zeta menerangkan arti dan makna dari ramburambu lalu lintas yang sering dijumpai di jalan. Juga ada contohnya rambu-rambu lalu lintas tersebut ditaman Pacantells. Ada petugas dari Dinas Perhubungan Kabupaten Bandung yang menjelaskan makna dari rambu-rambu lalu lintas yang dipandu oleh Dimas dan Zeta dengan pembawaan yang menyenangkan dan ringan yang cocok dengan gaya komunikasi anak usia dini.

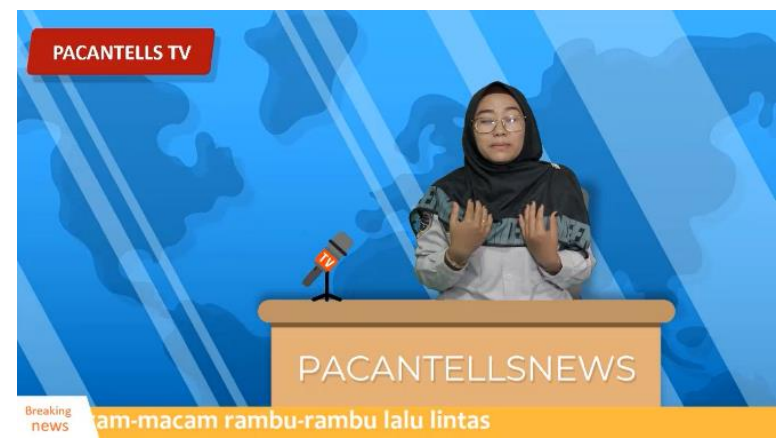

Gambar 12. Petugas Dishub Kab. Bandung yang Sedang Menjelaskan Rambu Lalu Lintas

Sumber: Dinas Perhubungan Kab. Bandung, 2020

Dapat digambarkan bahwa proses kreatif dari animasi 2D motion graphic Dimas dan Zeta yang mana bertujuan membawa nilai pendidikan berlalu lintas berhasil. Data diambil dari hasil wawancara dengan para orang tua yang membawa anak-anak mereka berkunjung ke Taman Pacantells untuk bermain dan menyaksikan tayangan animasi Dimas dan Zeta di Taman Pacantells, dapat dilihat juga dari ekspresi para anak-anak usia dini yang datang menyaksikan dan respon mereka merasa sangat terbantu dan juga terhibur setelah menyaksikan tayangan animasi Dimas dan Zeta. Salah satu indikator lainnya adalah kemampuan anak-anak usia dini menjawab kuis seputar lalu lintas di akhir sesi tayangan animasi 2D motion graphic Dimas dan Zeta. Berikut penulis membuat alur proses kreatif dari mulai proses perancangan sampai tujuan dan maksud dari perancangan animasi 2D Dimas dan Zeta.

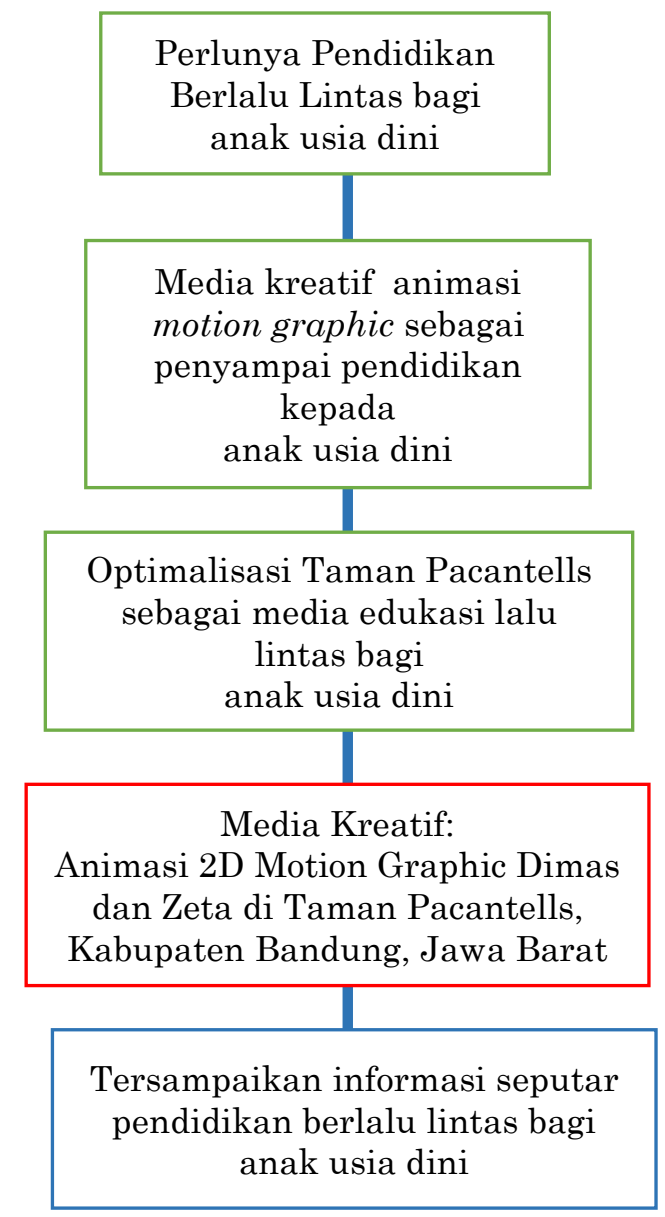

Gambar 13. Proses Implementasi Transfer Pendidikan Berlalu Lintas Melalui Media Animasi Dimas dan Zeta

Dalam animasi 2D motion graphic Dimas dan Zeta, karakter Dimas dan Zeta juga membawakan langsung materinya dengan cara yang menarik dan cocok untuk perkembangan anak usia dini. Dimas membawakan tata cara 
bagaimana berjalan kaki dijalan kemudia disusul Zeta membawakan materi bagaimana cara menyeberang yang baik dan aman.

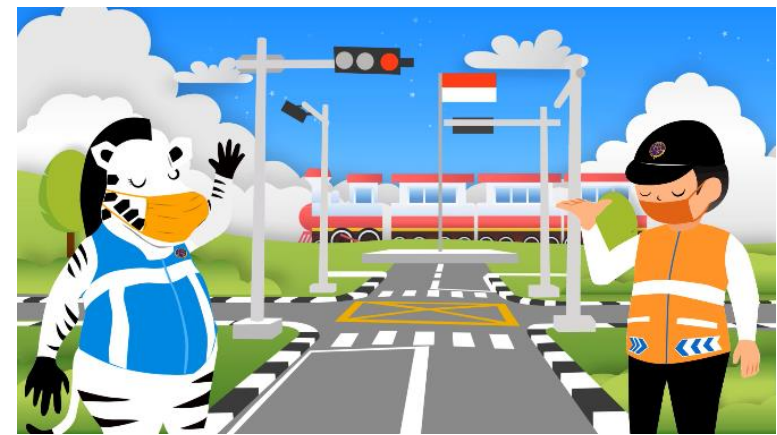

Gambar 14. Taman Pacantells dalam Animasi Dimas dan Zeta

Sumber: Dinas Perhubungan Kab. Bandung, 2020.

Untuk mengetahui berhasil atau tidaknya transfer nilai pendidikan berlalu lintas sampai ke anak-anak usia dini yang menyaksikan, maka dibawakan lagu dan juga kuis di sesi akhir agar lebih tersampaikan lagi tentang tata cara berlalu lintas yang baik dan benar bagi anak usia dini.

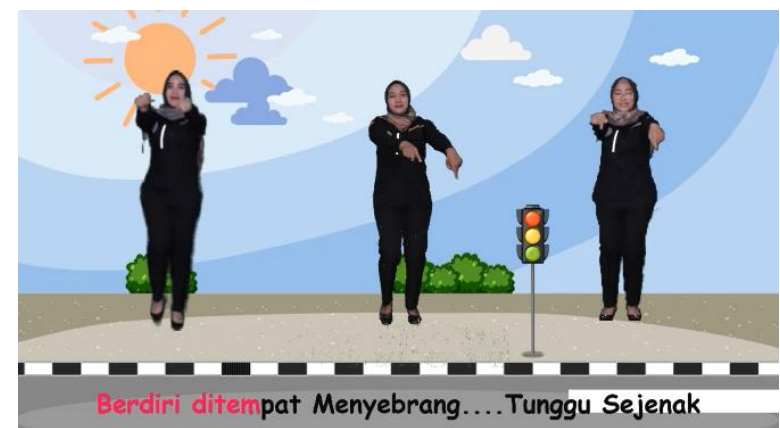

Gambar 15. Pesan-Pesan Berlalu Lintas Bagi Anak Usia Dini Dibawakan Dengan Lagu dan Gerakan Senam

Sumber: Dinas Perhubungan Kab. Bandung, 2020.

Penulis menganalisis karakter yang sudah ada karena sudah terbukti berhasil dan memberikan dampak pada transfer nilai-nilai pendidikan khususnya pada aspek transfer nilai pendidikan berlalu lintas bagi anak-anak usia dini. Karakter Dimas dan Zeta yang sudah eksis dan berhasil menyampaikan transfer nilai-nilai pendidikan berlalu lintas di Taman Pacantells dapat menjadi role model bagi media pembelajaran sejenis yang juga menggunakan media berbasis karakter untuk menyampaikan nilai-nilai pendidikan. Karakter Dimas dan Zeta pada tayangan animasi Dimas dan Zeta terbukti berhasil menjadi media kreatif penyampai nilai-nilai pendidikan berlalu lintas pada anak usia dini di Taman Pacantells.
Dinas Perhubungan Kabupaten Bandung sebagai pemegang hak cipta karakter Dimas dan Zeta sangat senang dengan tanggapan dan respon pengunjung Taman Pacantells pada tayangan animasi Dimas dan Zeta. Dinas Perhubungan Kabupaten Bandung berharap kedepan ada pengembangan dari tayangan animasi Dimas dan Zeta dan bisa membuat produk edukasi lain dari karakter Dimas dan Zeta.

Media kreatif terbukti sangat efektif dalam penyampaian nilai-nilai dan tujuan pendidikan. Pemakaian media pembelajaran dalam proses belajar dapat membangkitkan keinginan dan minat yang baru, membangkitkan motivasi dan rangsangan kegiatan belajar, dan bahkan membawa pengaruh psikologis terhadap siswa atau peserta didik (Arsyad, 2010). Rata-rata peningkatan hasil belajar peserta didik yang menggunakan multimedia animasi juga lebih tinggi dibandingkan dengan rata-rata peningkatan hasil belajar peserta didik yang menggunakan media visual gambar diam (Asyhar, 2012).

\section{Simpulan dan Saran}

Dari pemaparan di atas dapat disimpulkan bahwa dengan media animasi 2D motion graphic Dimas dan Zeta dicapai keberhasilan dalam menyampaikan informasi dan pendidikan berlalu lintas bagi anak usia dini di Taman Pacantells. Media animasi terbukti efektif menyampaikan nilai-nilai pendidikan dengan cara yang menarik tetapi juga tepat sasaran memberikan transfer pengetahuan seputar lalu lintas kepada anak usia dini, yaitu tata cara menyeberang dijalan, tata cara berjalan kaki dijalan dan membaca rambu-rambu lalu lintas dijalan.

Diharapkan ke depan media animasi untuk pendidikan semakin digencarkan dan semakin masif lagi. Karena selain menghibur, media kreatif seperti ini juga sangat pas untuk semua kalangan termasuk anak usia dini. Juga efektif menyampaikan nilai-nilai pendidikan.

\section{Daftar Pustaka}

Arsyad, A. (2010). Media pembelajaran. Jakarta : PT. Raja Grafindo Persada.

Asyhar, R. (2012). Kreatif Mengembangkan Media Pembelajaran. Jakarta: Referensi

Azwandi, Y. (2007). Media Pembelajaran Anak Berkebutuhan Khusus. Departemen Pendidikan 
Nasional Direktorat Jendral Pendidikan Tinggi Direktorat Ketenagaan. Jakarta

Darojah, R. U. (2011). "Peningkatan Kemampuan BerbicaraMelaporkan dengan Media Film Animasi pada Siswa Kelas VIII SMPN 12 Yogyakarta”. Skripsi. UNY, Yogyakarta. http://eprints.uny.ac.id/1296/1/Ridan_07201 241029.pdf.Diakses tanggal 24 Maret 2021.

Fauziddin, M. (2018). Useful of Clap Hand Games for Optimalize Cogtivite Aspects in Early Childhood Education. Jurnal Obsesi: Jurnal Pendidikan Anak Usia Dini, 2(2).

Hasanah, U., \& Nulhakim, L. (2015). Pengembangan Media Pembelajaran Film Animasi sebagai Media Pembelajaran Konsep Fotosintesis. Jurnal Penelitian dan Pembelajaran IPA, 1(1), 91-106.

Indonesia, R. Undang-Undang Nomor 20 Tahun 2003, 41 (2003).

Kemendikbud, R. I. (2014). Permendikbud
Nomor 137 Tahun 2014 Tentang Standar Nasional Pendidikan Anak Usia Dini.

Khaironi, M. (2018). Perkembangan Anak Usia Dini. Jurnal Golden Age Hamzanwadi University, 3(1), 1-12.

Maleong, J. Lexy. (2016). Metodologi Penelitian Kualitatif. Bandung: Alfabeta.

Raimukti. (2013). Perkembangan Film Animasi di Indonesia. http://repository.stisitelkom.ac.id/ 72/2/Pekembangan_film_animasi_di_indone sia.pdf. Diakses tanggal 24 Maret 2021.

Sanjaya, W. (2009). Kurikulum dan Pembelajaran: Teori dan Praktik Pengembangan Kurikulum Tingkat Satuan Pendidikan (KTSP). Kencana Prenada Media Group. Bandung.

Suheri, A (2006). Animasi Media Pembelajaran. Jurnal Animasi Multimedia Pembelajaran. $2,(1), 27-33$

Sugiono. (2015). Metodologi Penelitian Kualitatif. Bandung: Alfabeta. 